\title{
Advanced Byproduct Recovery: \\ Direct Catalytic Reduction of Sulfur Dioxide to Elemental Sulfur
}

Fifth Quarterly

Technical Progress Report

\author{
Report to \\ Department of Energy \\ Pittsburgh Energy Technology Cente \\ Under Contract \# \\ DE-AC-95PC95252
}

December, 1996

Arthur D. Little, Inc.

Acorn Park

Cambridge, Massachusetts

02140-2390

Tufts University

Medford, Massachusetts

02155

Reference 54177 
Table of Contents

INTRODUCTION

$\begin{array}{ll}\text { Background } & 5\end{array}$

Description of Byproduct Recovery System 5

$\begin{array}{ll}\text { Research and Development Activity } & 6\end{array}$

WORK BREAKDOWN STRUCTURE $\quad 8$

$\begin{array}{lr}\text { Phase I Task 1: Market, Process and Cost Evaluation } & 8\end{array}$

Phase I Task 2: Lab-Scale Catalyst Testing/Optimization 9

$\begin{array}{ll}\text { Phase I Task 3: Catalyst Preparation and Costing } & 10\end{array}$

Phase I Task 4: Bench-scale Testing $\quad 11$

Phase I Task 5: Utility Review $\quad 12$

Phase I Task 6: Management and Reports 12

OBJECTIVES FOR FIFTH QUARTER ACTIVITY 12

FIFTH QUARTER TECHNICAL PROGRESS 13

$\begin{array}{ll}\text { Background } & 13\end{array}$

$\begin{array}{ll}\text { Tufts } & 14\end{array}$

$\begin{array}{ll}\text { Arthur D. Little } & 17\end{array}$

$\begin{array}{ll}\text { Engelhard } & 19\end{array}$

REFERENCES: $\quad 19$ 


\section{List of Figures}

Figure 1-1: Regenerable Sorbent System

Figure 1-: Work Elements

Figure 4-1. Effect of pre-reduction on the activity of $\mathrm{CeO}_{2}$ (La). Reaction conditions: $1 \% \mathrm{SO}_{2}, 0.5 \% \mathrm{CH}_{4}$, balance $\mathrm{He}, 0.36 \mathrm{~g} \mathrm{~s} / \mathrm{cm}^{3}$.

Figure 4 2. Effect of adding water on the activity of $\mathrm{CeO}_{2}$. Samples were calcined at $650^{\circ} \mathrm{C}$. Reaction conditions: $1 \% \mathrm{SO}_{2}, 0.5 \% \mathrm{CH}_{4}, 12 \% \mathrm{H}_{2} \mathrm{O}$, contact time $=0.36 \mathrm{~g} \mathrm{~s} / \mathrm{cm}^{3}$.

Figure 4- 3. Demonstration of the recovery in the activity of $\mathrm{CeO}_{2}$ when water is removed from the feed stream. Conditions for the first 17 hours were the same as those in Figure 4-2. 


\section{List of Tables}

Table 4-1. Physical Properties and Activity of Ceria and Doped Ceria 


\section{Introduction}

\section{Background}

More than 170 wet scrubber systems applied, to 72,000 MW of U.S., coal-fired, utility boilers are in operation or under construction. ${ }^{4}$ In these systems, the sulfur dioxide removed from the boiler flue gas is permanently bound to a sorbent material, such as lime or limestone. The sulfated sorbent must be disposed of as a waste product or, in some cases, sold as a byproduct (e.g. gypsum). Due to the abundance and low cost of naturally occurring gypsum, and the costs associated with producing an industrial quality product, less than $7 \%$ of these scrubbers are configured to produce useable gypsum ${ }^{1}$ (and only $1 \%$ of all units actually sell the byproduct). The disposal of solid waste from each of these scrubbers requires a landfill area of approximately 200 to 400 acres. In the U.S., a total of 19 million tons of disposable FGD byproduct are produced, transported and disposed of in landfills annually. ${ }^{6}$

The use of regenerable sorbent technologies has the potential to reduce or eliminate solid waste production, transportation and disposal. In a regenerable sorbent system, the sulfur dioxide in the boiler flue gas is removed by the sorbent in an adsorber. The $\mathrm{SO}_{2}$ is subsequently released, in higher concentration, in a regenerator. All regenerable systems produce an off-gas stream from the regenerator that must be processed further in order to obtain a saleable byproduct, such as elemental sulfur, sulfuric acid or liquid $\mathrm{SO}_{2}$. A schematic of a regenerable sorbent system is shown below.

Figure -: Regenerable Sorbent System

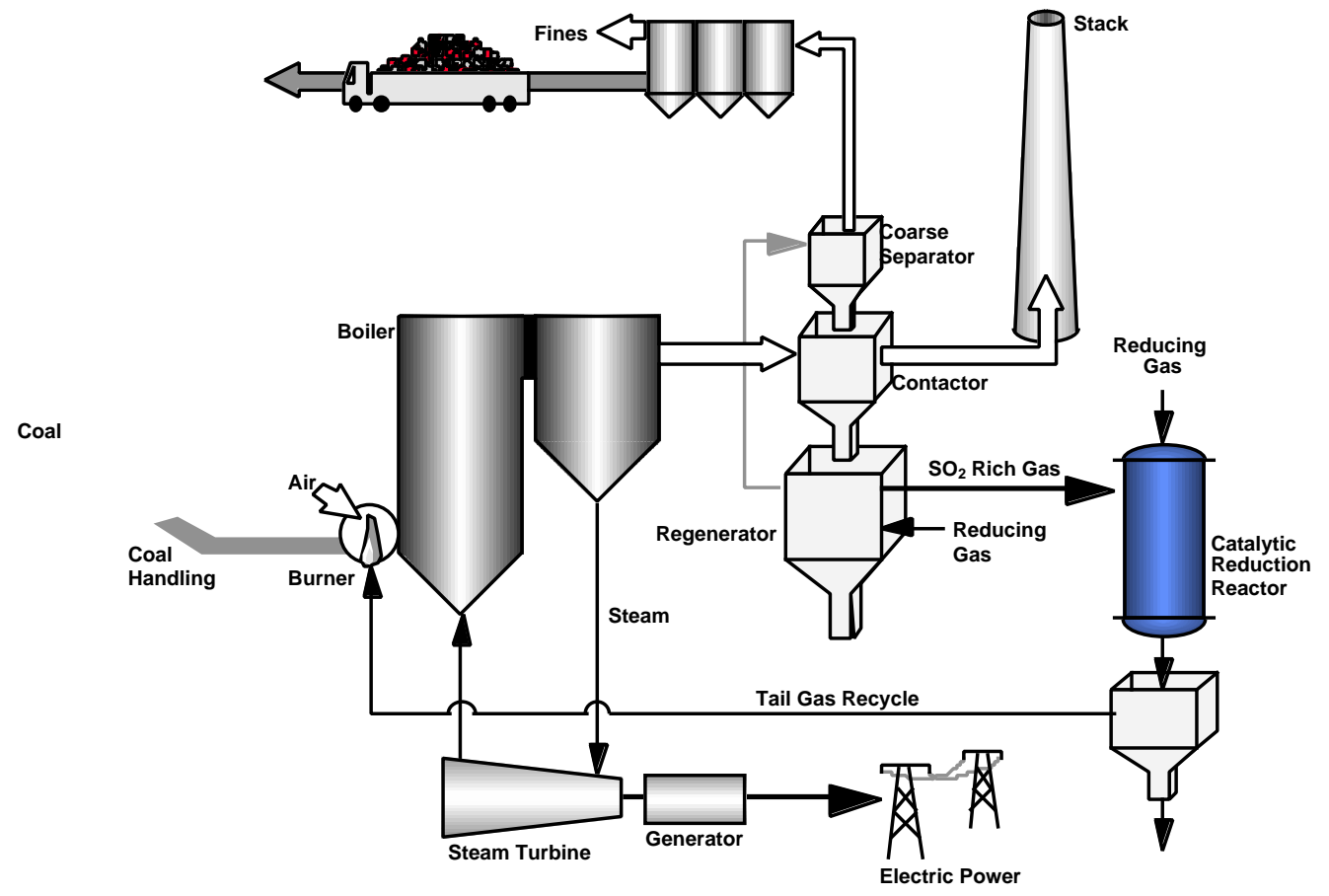

In addition to reducing solid waste, many regenerable systems have other benefits compared to non-regenerable scrubbing technologies, including higher sulfur removal efficiencies, and the capability of combined $\mathrm{SO}_{2} / \mathrm{NO}_{\mathrm{x}}$ removal.

\section{Description of Byproduct Recovery System}

The team of Arthur D. Little, Tufts University and Engelhard Corporation are conducting Phase I of a four and a half year, two-phase effort to develop and scale-up an advanced byproduct 
recovery technology that is a direct, single-stage, catalytic process for converting sulfur dioxide to elemental sulfur. This catalytic process reduces $\mathrm{SO}_{2}$ over a fluorite-type oxide (such as ceria and zirconia). The catalytic activity can be significantly promoted by active transition metals, such as copper. More than $95 \%$ elemental sulfur yield, corresponding to almost complete sulfur dioxide conversion, was obtained over a $\mathrm{Cu}-\mathrm{Ce}-\mathrm{O}$ oxide catalyst as part of an on-going DOEsponsored, University Coal Research Program (at MIT with Dr. Flytzani-Stephanopoulos). This type of mixed metal oxide catalyst has stable activity, high selectivity for sulfur production, and is resistant to water and carbon dioxide poisoning. Tests with $\mathrm{CO}$ and $\mathrm{CH}_{4}$ reducing gases indicate that the catalyst has the potential for flexibility with regard to the composition of the reducing gas, making it attractive for utility use. The performance of the catalyst is consistently good over a range of $\mathrm{SO}_{2}$ inlet concentration (0.1 to 10\%) indicating its flexibility in treating $\mathrm{SO}_{2}$ tail gases as well as high concentration streams.

\section{Research and Development Activity}

Arthur D. Little, Inc., together with its industry and commercialization advisor, Engelhard Corporation, and its university partner, Tufts, plans to develop and scale-up an advanced, byproduct recovery technology that is a direct, catalytic process for reducing sulfur dioxide to elemental sulfur. The principal objective of our Phase I program is to identify and evaluate the performance of a catalyst which is robust and flexible with regard to choice of reducing gas.

In order to achieve this goal, we have planned a structured program including:

Market/process/cost/evaluation;

Lab-scale catalyst preparation/optimization studies;

Lab-scale, bulk/supported catalyst kinetic studies;

Bench-scale catalyst/process studies; and

Utility Review

The flow of and interaction among the planned work elements are illustrated in for Phase I. A description of the methods of investigation to be used for these program elements is described below.

Market, Process and Cost Evaluation. Interviews will be conducted with electric utilities and regenerable sorbent system developers to define key market issues, such as: preferred reducing gas; variability of off-gas stream composition; system contaminants; emissions limitations; cost constraints; and reliability/durability issues. From the interview responses, key performance criteria for the system will be defined. The performance and cost of the proposed catalytic process will be evaluated and compared to these criteria. In addition, these performance criteria will be used to define milestones and to focus catalyst and process development. 
Figure -: Work Elements

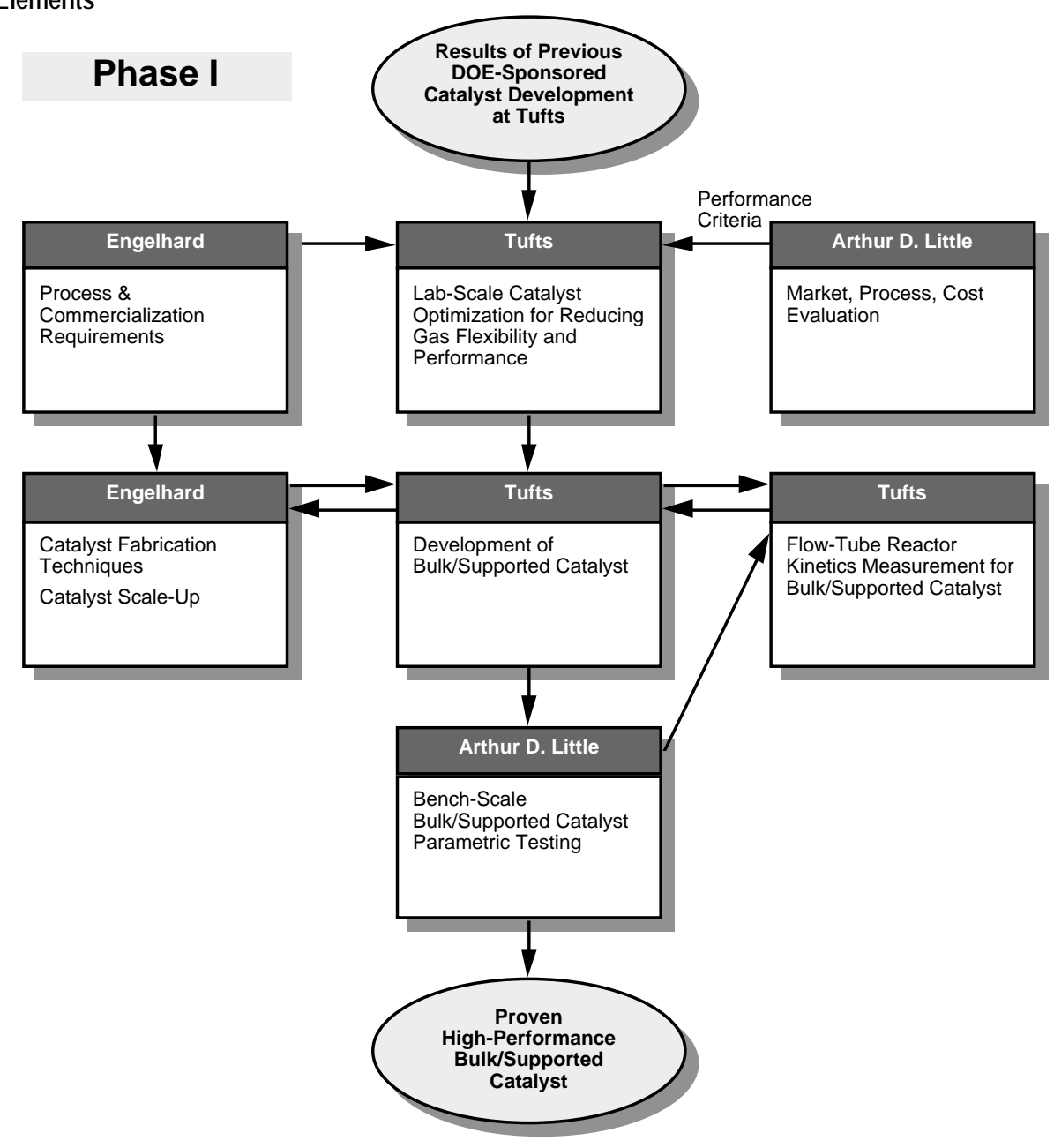

Lab-scale Catalyst Preparation/Optimization Studies. Catalyst will be prepared using a variety of methods (such as co-precipitation, sol-gel technique) from two candidate fluorite oxides $\left(\mathrm{CeO}_{2}, \mathrm{ZrO}_{2}\right)$ and four candidate transition metals $(\mathrm{Cu}, \mathrm{Co}, \mathrm{Ni}, \mathrm{Mo})$. These catalyst materials will be tested at Tufts in the same apparatus as was used in the previous work discussed above with a variety of reducing gases $\left(\mathrm{CO}, \mathrm{CO}+\mathrm{H}_{2}, \mathrm{CH}_{4}\right)$. Data will be gained in order to determine the key underlying reaction mechanisms. Parametric tests will determine the relative effects of temperature, concentration, space velocity, catalyst preparation method, and reducing gas. To reduce the amount of screening work, statistical experiment design methods will be used and catalyst characterization will be used to discriminate between active compositions. Some catalyst characterization work (x-ray diffraction, microscopy) will be conducted by Tufts staff at MIT laboratories.

Lab-scale, Bulk/Supported Catalyst Kinetic Studies. The best-performing catalysts will then be either appropriately supported (pellet, tablets, honeycomb, etc.) or formulated in bulk form. The bulk/supported catalyst will be tested in a laboratory-scale flow-tube reactor at Tufts to determine kinetic data.

Bench-scale Catalyst/Process Studies. Larger quantities of the bulk/supported catalyst will be tested in a bench-scale flow tube reactor at Arthur D. Little. Parametric tests will be conducted to 
assess the influence of temperature, inlet $\mathrm{SO}_{2}$ concentration, space velocity, and choice of reducing gas on performance. Some cyclic and duration testing will also be conducted at this scale.

Utility Review. A utility review team will be assembled, consisting of one or more utilities that have experience with regenerable desulfurization technologies or are considering their application in the near future. We will work closely with the utilities to inform them of the developments and solicit their perspective on utility needs and development issues.

\section{Work Breakdown Structure}

\section{Phase I Task 1: Market, Process and Cost Evaluation}

\section{Lead Contractor: Arthur D. Little}

\section{Objectives:}

To identify the critical market forces, technical requirements and cost constraints in order to focus the catalyst/byproduct recovery process research effort;

To evaluate the costs and benefits of the advanced byproduct recovery process, and to compare these attributes to those of state-of-the-art technologies;

To determine the extent to which application of the advanced byproduct recovery process improves the competitiveness of regenerable sorbent systems.

\section{Approach:}

This task is being conducted by Arthur D. Little. We are interviewing utilities, leading architect/engineering companies, regenerable sorbent system developers, industry consultants and EPRI to define key market issues, including: preferred reducing gas; variability of $\mathrm{SO}_{2}$-rich off-gas stream composition; compatibility/flexibility in coupling with the adsorption/regeneration step; system contaminants; emissions limitations; cost constraints; and reliability/durability issues. Based on these interviews, we will define the key performance criteria for the system. We will estimate the potential market for advanced, catalytic reduction of $\mathrm{SO}_{2}$ to elemental sulfur in utility and industrial applications.

We are preparing a Process Evaluation, in which we will prepare or specify process energy balances, temperature requirements, reactor volumes, and recycle rates, for one or more reducing gas production methods. These analyses will be tied to the requirements of utilities and the various regenerable sorbent technologies under development. We are also preparing a Cost Evaluation of the byproduct recovery system in the context of its use with one or more regenerable $\mathrm{SO}_{2}$ removal systems and compare the costs of the proposed technology to that of state-of-the-art technology.

\section{Deliverables:}

Market, process and cost analyses of the proposed byproduct recovery system; definition of key areas to focus research efforts; assessment of the potential market for the process. 


\section{Phase I Task 2: Lab-Scale Catalyst Testing/Optimization}

\section{Lead Contractor: Tufts}

\section{Objectives:}

To optimize catalyst composition and preparation method for use with a variety of reducing gas compositions and qualities, including syn-gas and natural gas.

\section{Approach:}

This task is being carried out by Tufts University, a subcontractor to Arthur D. Little. Under four subtasks, Tufts will prepare and characterize the catalysts, conduct adsorption/desorption studies, measure catalytic activity in a packed-bed microreactor, and conduct parametric tests and kinetic measurements. Specifically, Tufts will optimize the catalyst composition and preparation method for use with a variety of reducing gas compositions and qualities, including synthesis gas and natural gas.

The transition metal-promoted fluorite-type oxides previously identified as very active and selective catalysts for the reduction of $\mathrm{SO}_{2}$ to elemental sulfur with carbon monoxide will be tested with other reductants, namely synthesis gas $\left(\mathrm{H}_{2}\right.$ and $\mathrm{CO}$ mixed with $\mathrm{H}_{2} \mathrm{O}$ and $\left.\mathrm{CO}_{2}\right)$ and natural gas. Various transition metals (including $\mathrm{Cu}, \mathrm{Co}, \mathrm{Ni}$, and $\mathrm{Mo}$ ) will be examined as promoters to obtain a catalyst composition active in various reducing gases. The fluorite oxides to be used in this work are ceria $\left(\mathrm{CeO}_{2}\right)$ and zirconia $\left(\mathrm{ZrO}_{2}\right)$.

Arthur D. Little, with assistance from Tufts, will develop a detailed Test Plan for the laboratoryscale catalyst testing and optimization activities. The Test Plan will be submitted as an amendment to the Management Plan. No testing will begin until the Test Plan has been approved by the DOE Project Manager.

Catalyst Preparation and Characterization Tufts will prepare the catalysts by the coprecipitation method to produce a surface area in the range of $20-60 \mathrm{~m}^{2} / \mathrm{g}$. To achieve high surface area, high elemental dispersion, and uniform pore-size distribution, other preparation techniques (such as gelation and impregnation of high surface area supports) will also be examined.

Catalysts will routinely be characterized by X-ray powder diffraction for crystal phase identification and by nitrogen adsorption/desorption for BET surface area and pore size distribution measurements. The elemental composition of the catalyst will be analyzed Inductively Coupled Plasma Atomic Emission Spectrometry. Selected active catalysts will be further characterized by X-ray Photoelectron Spectroscopy (XPS) and Scanning Transmission Electron Microscopy (STEM).

Adsorption/Desorption Studies In parallel with the preparation of the new catalyst composition, the $\mathrm{Cu}-\mathrm{Ce}-\mathrm{O}$ catalyst will be evaluated in adsorption/desorption studies with $\mathrm{CO}, \mathrm{COS}$, and $\mathrm{SO}_{2}$ to determine the reaction mechanism. These experiments will lead to an understanding of the low selectivity of this catalyst to the undesirable byproduct COS and facilitate catalyst optimization. A thermo-gravimetric analyzer, coupled with a residual gas analyzer, will be used for these tests.

Catalytic Activity Measurements in a Packed-Bed Microreactor Tufts will conduct catalyst activity tests under steady conditions in an existing packed- bed microreactor. Screening tests will be conducted with a reducing gas consisting of $1 \% \mathrm{SO}_{2}$ and $0.5 \% \mathrm{CH}_{4}$. Additional tests of 
the most promising catalysts will be conducted with two additional synthesis reducing gases. However, final selection of reducing gases will be made based on input from regenerable sorbent system developers and utilities (the Task 1 findings). We currently envision the two additional synthesis test gases to be:

(i) wet feed gas mixture containing $1 \% \mathrm{SO}_{2}$ and stoichiometric amount of synthesis gas with $\mathrm{H}_{2} / \mathrm{CO}=0.3,2 \% \mathrm{H}_{2} \mathrm{O}$ and $2 \% \mathrm{CO}_{2}$; and

(ii) wet feed gas mixture containing $1 \% \mathrm{SO}_{2}$, stoichiometric amount of synthesis gas with $\mathrm{H}_{2} / \mathrm{CO}=3,2 \% \mathrm{H}_{2} \mathrm{O}$, and $2 \% \mathrm{CO}_{2}$.

The existing data on performance with pure $\mathrm{CO}$ and the new data to be developed using methane and wet synthesis gases will cover the range of possible regeneration gases available. It is not necessary to test dry synthesis gases since the tests with $\mathrm{CO}$ and methane provides information on ideal performance without water. For each reacting gas mixture, the reactor temperature will be increased and then reduced to establish light-off and fall-off behavior of each catalyst. Elemental sulfur yield, catalyst activity and catalyst selectivity will be used to identify the most promising catalysts.

Parametric Studies and Kinetic Measurements After identifying promising catalysts, an extensive parametric study and kinetic measurements will be carried out to provide reactor design information. The parametric studies will address:

(i) the effects of water vapor and/or carbon dioxide on catalyst activity and elemental sulfur yield; and

(ii) effect of reducing gas composition $\left(\mathrm{H}_{2} / \mathrm{CO}\right.$ ratios/ $\left.\mathrm{CH}_{4}\right)$ on catalyst activity and sulfur yield.

Long-term and hydrothermal catalyst stability will be evaluated for the preferred catalyst composition in Task 4, Bench-Scale Testing.

The parametric studies will be conducted at space velocities in the range 1,000 to $100,000 \mathrm{~h}^{-1}$, $\mathrm{SO}_{2}$ concentrations from $0.1 \%$ to $10 \%, \mathrm{H}_{2} \mathrm{O}$ contents from 0 to $10 \%, \mathrm{H}_{2} / \mathrm{CO}$ ratios from 0 to 3 , and $\mathrm{CH}_{4}$ concentrations from $0.1 \%$ to $10 \%$. The temperature will be in the range 50 to $700^{\circ} \mathrm{C}$. A kinetic model will be developed from the data obtained at short contact time $(<0.1 \mathrm{~g} \mathrm{~s} / \mathrm{cc})$ in a small diameter catalytic reactor. This will include the effects of $\mathrm{H}_{2} \mathrm{O}$ and $\mathrm{CO}_{2}$ on the specific activity.

Deliverables:

An optimized catalyst composition/preparation method for bench-scale catalyst tests. Kinetic data for use in reactor design.

\section{Phase I Task 3: Catalyst Preparation and Costing \\ Lead Contractor: Engelhard}

\section{Objectives:}

Provide guidance regarding the establishment of activity and simulated aging tests to quickly and efficiently determine performance characteristics of catalyst formulations;

To prepare supported or bulk (extruded) catalysts in the form of pellets or honeycombs for bench-scale testing; 
To provide catalyst manufacturing and cost analysis for inclusion in the analysis of process economics.

\section{Approach:}

Engelhard will work closely with Tufts and Arthur D. Little to specify the appropriate catalyst structures to meet the engineering requirements for the targeted sulfur recovery systems.

Included in this activity will be the training of scientists and engineers on the Tufts team by Engelhard staff members in the formulation of commercially viable catalyst structures.

Engelhard staff will observe and participate in laboratory-scale and bench-scale testing at Tufts and Arthur D. Little to interpret/analyze results. The resulting analysis will be used to redesign catalysts which resist deactivation.

Engelhard will apply their expertise in process and cost evaluation of catalytic systems to the sulfur byproduct recovery system. Engelhard will provide catalyst manufacturing cost details to allow the process economics to be established.

\section{Deliverables:}

Catalysts for bench-scale testing; manufacturing/cost analysis of catalysts for inclusion in system evaluation task.

\section{Phase I Task 4: Bench-scale Testing}

\section{Lead Contractor: Arthur D. Little}

\section{Objectives:}

To conduct bench-scale, parametric tests to evaluate the performance of three to five supported/extruded catalyst preparations.

\section{Approach:}

Arthur D. Little will develop a Test Plan for the bench-scale parametric tests and will incorporate this plan into an amendment to the Management Plan. No work will begin on the bench-scale tests until the Test Plan has been approved by the DOE Project Manager. Arthur D. Little is designing, and will fabricate and commission a bench-scale $\mathrm{SO}_{2}$ reduction reactor facility. The facility will consist of gas supply controls (for the simulated regenerator off-gas stream and the reducer gas stream); gas heaters; a catalytic reduction reactor (approximately 1-2 1 in size); a heat exchanger for sulfur knock-out; gas analysis instrumentation $\left(\mathrm{SO}_{2}, \mathrm{H}_{2} \mathrm{~S}\right.$ on-line analyzers, gas chromatograph) and an afterburner for clean-up of off-gases. The system will be fabricated and shaken-down in the first 6 months of the program following approval of the Management Plan.

We will initiate bench-scale tests using the catalyst materials that have been proven as highly active and selective for sulfur production from the previous/ongoing catalyst development programs: a copper promoted ceria catalyst, $\mathrm{Ce}-\mathrm{Cu}-\mathrm{O}$. Tests on supported materials will reveal the performance changes associated with the use of supported or bulk extruded materials compared to powders. We will investigate the effects of space velocity, temperature, and reducer gas and regenerator gas composition on catalyst performance. 
Subsequent parametric tests will be performed on catalyst formulations selected from the labscale catalyst optimization work. The operating variables are expected to be as follows: space velocity: $10,000,25,000,50,000 \mathrm{hr}^{-1}$; temperature: $450,500,600^{\circ} \mathrm{C}$; inlet stream composition: $\mathrm{SO}_{2}$ concentration: 0.1 to $10 \% ; \mathrm{H}_{2} \mathrm{O}$ concentration 2 to $30 \% ; \mathrm{CO}_{2}$ concentration 2 to $30 \%$; reducing gas composition: $\mathrm{CO} / \mathrm{H}_{2}$ ratio: 0.5 to $3.0 ; \mathrm{CO} / \mathrm{CO}_{2}$ ratio: 0.5 to 3.0. Information developed from this task will provide insights for the process evaluation task, the catalyst optimization work, and the Phase II efforts in reactor scale-up.

\section{Deliverables:}

Performance map for 3 to 5 catalyst preparations; selection of catalyst preparation for dynamic response and pilot-scale testing.

\section{Phase I Task 5: Utility Review \\ Lead Contractor: Arthur D. Little}

\section{Objectives:}

To provide electric utility perspective and review of development program

To focus development effort on issues of key importance to utilities

\section{Approach:}

We will identify a utility review team, consisting of one or more utilities that have experience with regenerable desulfurization technologies or are considering their application in the near future. We will work closely with the utilities to inform them of the developments and solicit their perspective on utility needs and development issues. We plan to communicate through monthly meetings and will share data as it becomes available. Possible Utility Review Team members are Niagara Mohawk, Public Service of New Mexico, and Ohio Edison. All these utilities are participants in either regenerable sorbent programs or Clean Coal Development programs and would therefore have a valuable perspective to provide to our program, and would have a stake in the development of an improved byproduct recovery system.

\section{Deliverables:}

Utility review of the bench-scale developments; input to developments concerning issues of key importance to utilities.

\section{Phase I Task 6: Management and Reports}

\section{Lead Contractor: Arthur D. Little}

This task will be conducted by Arthur D. Little and will involve coordinating the catalyst/process development effort, coordinating the activities of the prime contractor and two subcontractors, and preparing the monthly, quarterly, topical, and final reports for DOE.

\section{Objectives for Fifth Quarter Activity}

The objectives for the fifth quarter were to: 
Continue work on catalyst screening using the laboratory-scale packed bed reactor. Effects of dopant type, dopant level, reducing gas type, stoichiometry, and temperature on selectivity and activity of a range of fluorite-type catalysts will be assessed.

Continue to examine catalysts containing $\mathrm{Cu}, \mathrm{Co}, \mathrm{Ni}$ and Mo. High surface area $\left(150 \mathrm{~m}^{2} / \mathrm{g}\right)$ ceria samples recently obtained from Engelhard will be impregnated with nitrate salts of the metals under consideration. The performance of the supported catalysts will be compared to that of the bulk mixed oxide catalysts.

To examine the effect of water vapor on the best catalyst of each type. Other reducing gases, such as synthesis gas, will be tested.

To characterize catalysts by X-ray powder diffraction for crystal identification and by nitrogen adsoption/desorption for BET surface area and pore size distribution measurements. The elemental composition of the catalyst will be analyzed using Inductively Coupled Plasma Atomic Emission Spectrometry.

To complete the initial process, market and cost evaluation.

To complete fabrication of the bench-scale experiment, conduct shake-down tests and commence supported catalyst testing.

This report summarizes the results of the catalyst screening experiments at Tufts and the initial economic evaluation of the process.

\section{Fifth Quarter Technical Progress}

\section{Background}

In previous DOE-supported work, ${ }^{3}$ the activity and selectivity of fluorite-type oxides, such as ceria and zirconia, for reduction of $\mathrm{SO}_{2}$ were investigated. A wide range of transition metalimpregnated ceria and zirconia catalyst formulations were evaluated in a packed bed reactor, under both dry gas and wet gas $\left(2 \% \mathrm{H}_{2} \mathrm{O}\right)$ conditions. Under dry gas conditions, more than $95 \%$ yield of elemental sulfur and essentially complete $\mathrm{SO}_{2}$ conversion were obtained for a variety of catalysts. Under wet gas conditions, $\mathrm{Cu} / \mathrm{CeO}_{2}$ catalyst showed the lowest light-off temperature, the greatest resistance to water, and gave over $90 \% \mathrm{SO}_{2}$ conversion and more than $70 \%$ elemental sulfur yield.

Based on these results, and the fact that a 25 hour test indicated that the $\mathrm{Cu} / \mathrm{CeO}_{2}$ catalyst was stable at the reacting conditions, the $\mathrm{Cu}-\mathrm{Ce}-\mathrm{O}$ system was selected for detailed studies of the $\mathrm{SO}_{2}$ reaction with $\mathrm{CO}$. The effects of copper content, temperature, presence of water, and presence of $\mathrm{CO}_{2}$ on the selectivity and activity of this catalyst system were evaluated. This work led to the selection of bulk $\mathrm{Cu}_{0.15} \mathrm{Ce}_{0.85}(\mathrm{La}) \mathrm{O}_{\mathrm{x}}$ for further study. More than $95 \%$ elemental sulfur yield, corresponding to almost complete sulfur dioxide conversion, was obtained over a $\mathrm{Cu}-\mathrm{Ce}-\mathrm{O}$ oxide catalyst with a feed gas of stoichiometric composition $\left([\mathrm{CO}] /\left[\mathrm{SO}_{2}\right]=2\right)$ at temperatures above $450^{\circ} \mathrm{C}$. This catalyst showed no apparent deactivation during a 35-hour run in the presence of $2 \%$ water at $470^{\circ} \mathrm{C}$. In addition, the performance of this catalyst with other reducing gases was briefly investigated. Elemental sulfur yields of $50-66 \%$ were obtained using $\mathrm{H}_{2}$ at $600^{\circ} \mathrm{C}$ and an elemental sulfur yield of $72 \%$ was obtained using $\mathrm{CH}_{4}$ at $800^{\circ} \mathrm{C}$. It is noteworthy that all tests mentioned above were conducted at high space velocities, on the order of $40-50,000 \mathrm{~h}^{-1}(\mathrm{STP})$. 
Thus previous work has shown that the catalytic activity of fluorite-type oxides, such as ceria and zirconia, for the reduction of sulfur dioxide by carbon monoxide to elemental sulfur can be significantly promoted by active transition metals, such as copper. This type of mixed metal oxide catalyst has stable activity and is resistant to water and carbon dioxide poisoning. The performance of the catalyst was consistently good over a range of $\mathrm{SO}_{2}$ inlet concentration $(0.1$ to $10 \%$ ) indicating its flexibility in treating $\mathrm{SO}_{2}$ tail gases as well as high concentration streams.

The overall objective of the current two-phase program is build on the results described above to advance the $\mathrm{SO}_{2}$-reduction technology from the laboratory to commercial scale. The principal objective of our Phase I program is to identify and evaluate the performance of a catalyst which is robust and flexible with regard to choice of reducing gas (methane, carbon monoxide, or syngas).

\section{Tufts}

Work to date at Tufts University has focused on screening tests of a variety of catalyst formulations. The catalyst preparation technique used consists of mixing a solution of nitrate salts and urea and heating the solution to $100^{\circ} \mathrm{C}$ under strong stirring. Co-precipitation occurs as the solution is heated for $8 \mathrm{hr}$. The precipitate is then filtered, washed twice with hot deionized water, dried overnight, and then calcined in air at $650^{\circ} \mathrm{C}$ for $3 \mathrm{hr}$.

Previously reported results have indicated that:

$\mathrm{Ni}-\mathrm{Ce}(\mathrm{La})-\mathrm{O}$ catalysts show the highest activity, even at relatively low Ni concentrations (2\%).

$\mathrm{La}_{2} \mathrm{O}_{3}$ dopant plays a more important role in the reduction of $\mathrm{SO}_{2}$ by $\mathrm{CH}_{4}$ than in the reduction of $\mathrm{SO}_{2}$ by $\mathrm{CO}$.

Low metal contents are necessary to avoid agglomeration and sintering of the metal oxides at high temperatures.

Use of synthesis gas as the reducing agent can shift the catalyst light-off temperatures back to the values previously reported for pure CO.

The catalysts were prepared by urea gelation/coprecipitation. This method provides well dispersed and homogeneous mixed oxides or mixed oxide compounds, and was used in previous work and for some of the catalysts examined during this reporting period. This preparation consists of the following steps: (i) Mixing nitrate salts of metals with urea and heating the solution to $100^{\circ} \mathrm{C}$ under continuously stirring, (ii) After coprecipitation, boiling the resulting gels of Ce or Zr vigorously for 8 hours; (iii) Filtering and washing the precipitate twice with hot deionized water; (iv) Drying the precipitate overnight in a vacuum oven at $80-100{ }^{\circ} \mathrm{C}$; (v) Crushing the dried lumps into smaller particles and calcining in air for a few hours at $650{ }^{\circ} \mathrm{C}$ for $\mathrm{CeO}_{2}$-based catalysts and $500^{\circ} \mathrm{C}$ for $\mathrm{ZrO}_{2}$-based catalysts. The typical surface area of the thus prepared $\mathrm{CeO}_{2}$-based catalyst was about $70-120 \mathrm{~m}^{2} / \mathrm{g}$. However, the surface area of $\mathrm{CeO}_{2}$ and La$\mathrm{Ce}-\mathrm{O}$ catalysts was not stable even after $750{ }^{\circ} \mathrm{C}$ calcination, and the typical surface area after reaction up to $750{ }^{\circ} \mathrm{C}$ was around $35 \mathrm{~m}^{2} / \mathrm{g}$ (Table 1 ).

Table 1. Physical Properties and Activity of Ceria and Doped Ceria

\begin{tabular}{|c|c|c|c|c|c|c|}
\hline Sample & $\begin{array}{r}\text { Surf. area } \mathrm{o} \\
(\mathrm{n}\end{array}$ & esh sample & $\begin{array}{l}\text { Surf. area } \\
\text { after re }\end{array}$ & $\begin{array}{l}\text { ed sample* } \\
\text { at } 750^{\circ} \mathrm{C}\end{array}$ & \multicolumn{2}{|c|}{$\begin{array}{l}\text { Activity of Sample } \\
\left(\mathrm{T}=700^{\circ} \mathrm{C}\right)\end{array}$} \\
\hline & $\begin{array}{c}650{ }^{\circ} \mathrm{C} \\
\text { calcination }\end{array}$ & $\begin{array}{l}\quad 750^{\circ} \mathrm{C} \\
\text { calcination }\end{array}$ & dry & wet & $\mathrm{X}-\mathrm{SO}_{2}$ & $\mathrm{Y}-[\mathrm{S}]$ \\
\hline $\mathrm{CeO}_{2}$ & 75 & 40 & $29(20)$ & 33 & 0.255 & 0.255 \\
\hline
\end{tabular}




\begin{tabular}{lccllll}
\hline $4.5 \%$ La-Ce- & 70 & 59 & 33 & & 0.221 & 0.211 \\
O & & & & & 0.236 & 0.226 \\
10\%La-Ce-O & 106 & 69 & 37 & & 0.299 & 0.291 \\
20\%La-Ce-O & 120 & 58 & $34(30)$ & 28 & 0.206 & 0.198 \\
\hline
\end{tabular}

*all catalysts were pre-reduced (at $600{ }^{\circ} \mathrm{C}$ in $10 \% \mathrm{CO} / \mathrm{He}$ for $1 \mathrm{hr}$ ).

The values in parenthesis are the surface area of the samples calcined at $750{ }^{\circ} \mathrm{C}$.

All catalysts were tested in a laboratory-scale, quartz tube packed bed flow reactor with a porous quartz frit supporting the catalyst, which was in powder form. A 0.5 in. O.D. x 18.5 in. long bed was used in catalyst tests. The experiments were carried out under nearly atmospheric pressure. A cold trap connected at the outlet of the reactor was used to separate and collect the elemental sulfur and water from the product stream. The product gas was analyzed by a HP5880A Gas Chromatograph (GC) with a Thermal Conductivity Detector(TCD). A 1/4 in. O.D. x 6 in. long packed glass column of Chromosil 310 was used in the $\mathrm{GC}$ to detect $\mathrm{CO}, \mathrm{CO}_{2}, \mathrm{COS}, \mathrm{SO}_{2}, \mathrm{CS}_{2}$ and $\mathrm{H}_{2} \mathrm{~S}$.

The results are shown in terms of sulfur dioxide conversion, $\mathrm{X}-\mathrm{SO}_{2}$, and elemental sulfur yield, $\mathrm{Y}$-[S], defined as follows:

$$
\begin{gathered}
X\left(\mathrm{SO}_{2}\right)=\frac{\left(\left[\mathrm{SO}_{2}\right]_{0}-\left[\mathrm{SO}_{2}\right]\right)}{\left[\mathrm{SO}_{2}\right]_{0}} \\
Y(\mathrm{~S})=\frac{[\mathrm{S}]}{\left[\mathrm{SO}_{2}\right]_{0}}
\end{gathered}
$$

where $\left[\mathrm{SO}_{2}\right]_{0}$ and $\left[\mathrm{SO}_{2}\right]$ are the inlet and outlet sulfur dioxide concentrations, respectively, while $[\mathrm{S}]$ is the outlet elemental sulfur concentration. $[\mathrm{S}]$ is calculated from the difference:

$$
[\mathrm{S}]=\left[\mathrm{SO}_{2}\right]_{0}-\left[\mathrm{H}_{2} \mathrm{~S}\right]-[\mathrm{COS}]-\left[\mathrm{SO}_{2}\right]
$$

When pre-reduction was used, the fresh catalysts were pre-reduced by heating for one hour in $9.9 \% \mathrm{CO} / \mathrm{He}$ at $600{ }^{\circ} \mathrm{C}$. After activation, a gas mixture of $\mathrm{SO}_{2}-\mathrm{CH}_{4}-\mathrm{He}$ was introduced into the reactor and the temperature was raised from $400^{\circ} \mathrm{C}$ to $750^{\circ} \mathrm{C}$ in steps of $50-100{ }^{\circ} \mathrm{C}$. Water was injected into the heated gas line with a calibrated syringe pump. One or two temperatures were typically checked in the fall-off mode for hysteresis phenomena as well as potential catalyst deactivation. A gas mixture with a molar ratio of $\mathrm{SO}_{2} / \mathrm{CH}_{4}=2$ was used in the work reported here. The mole percent of $\mathrm{SO}_{2}$ in the feed gas was typically unity. The contact time was $0.36 \mathrm{~g} \cdot \mathrm{s} / \mathrm{cc}(\mathrm{NTP})$, and space velocity varied for different catalysts depending on the catalyst density.

Figure 4-1 shows the experimental activity data for $\mathrm{SO}_{2}$ reduction by $\mathrm{CH}_{4}$ on the bulk $\mathrm{CeO}_{2}$ catalyst and $\mathrm{La}-\mathrm{Ce}-\mathrm{O}$ catalysts. The pre-reduction of catalyst in $10 \% \mathrm{CO} / \mathrm{He}$ at $600{ }^{\circ} \mathrm{C}$ was not effective for $\mathrm{CeO}_{2}$, and $\mathrm{CeO}_{2}$ without pre-reduction showed the highest $\mathrm{SO}_{2}$ conversion, implying that surface oxygen species participates in activating methane. This is in agreement with the literature ${ }^{5}$ which suggests that the activation of methane occurs through surface lattice oxygen and surface coordinatively unsaturated (cus) oxygen. The pre-reduction of $\mathrm{CeO}_{2}$ inhibited the adsorption of methane due to the lack of available cus oxygen and surface oxygen species. However, the selectivity of non-pre-reduced $\mathrm{CeO}_{2}$ was lower than that of the pre-reduced one due to higher $\mathrm{H}_{2} \mathrm{~S}$ and $\mathrm{COS}$ formation. 

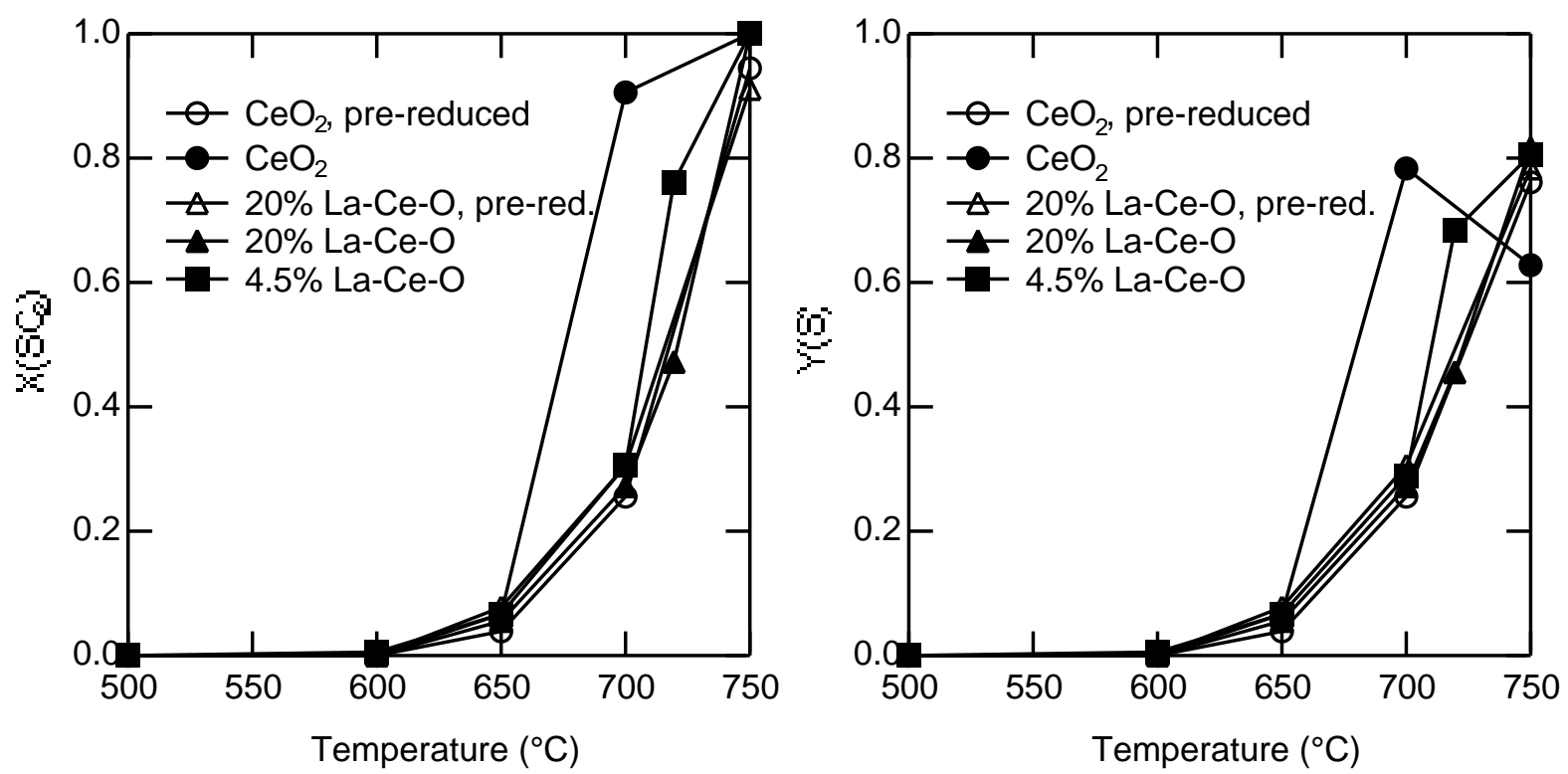

Figure 4-1. Effect of pre-reduction on the activity of $\mathrm{CeO}_{2}(\mathrm{La})$. Reaction conditions: $1 \% \mathrm{SO}_{2}$, $0.5 \% \mathrm{CH}_{4}$, balance $\mathrm{He}, 0.36 \mathrm{~g} \mathrm{~s} / \mathrm{cm}^{3}$.

For $4.5 \% \mathrm{La}-\mathrm{Ce}-\mathrm{O}$ catalyst, the pre-reduction slightly improved the activity of the catalyst, while for $20 \% \mathrm{La}-\mathrm{Ce}-\mathrm{O}$ catalyst, the pre-reduction had negligible effect. Both of these catalysts were less active than $\mathrm{CeO}_{2}$. Under reaction conditions, the catalysts surface is partially sulfated, and $\mathrm{SO}_{3}$ may be formed by reaction with the surface oxygen and making it more difficult to be reduced. This point warrants further investigation. At any rate $\mathrm{CH}_{4}$ and $\mathrm{SO}_{2}$ may be competing for the surface oxygen. The existence of oxygen vacancies at the lower temperature may not be desirable, as it can not activate $\mathrm{CH}_{4}$ in the presence of strongly bound $\mathrm{SO}_{2}$. The pre-reduction effect on the activity of $\mathrm{CeO}_{2}$ and $\mathrm{La}-\mathrm{Ce}-\mathrm{O}$ catalysts also indicates that the reduction of $\mathrm{SO}_{2}$ by methane follows a different mechanism from the $\mathrm{SO}_{2}$ reduction by $\mathrm{CO}$, which is believed to be redox mechanism. ${ }^{2}$

The introduction of water vapor in the reacting atmosphere may affect the catalytic activity by adsorption of $\mathrm{H}_{2} \mathrm{O}$ on the catalyst surface. Figure 4-2 shows that by adding $12 \%$ water vapor, more than $80 \%$ and $60 \% \mathrm{SO}_{2}$ conversion of $\mathrm{CeO}_{2}$ was lost at $700^{\circ} \mathrm{C}$ and $750{ }^{\circ} \mathrm{C}$, respectively, when compared to the dry condition. The activity could be recovered by removing water vapor from the reacting gas, as illustrated in Figure $4-3$. At $720^{\circ} \mathrm{C}$, by removing the water vapor from the feed gas, $\mathrm{SO}_{2}$ conversion was increased from 0.2 to 0.8 within 30 minutes. Additional temperatures have not been studied yet. The water effect will continue to be examined in future tests. 


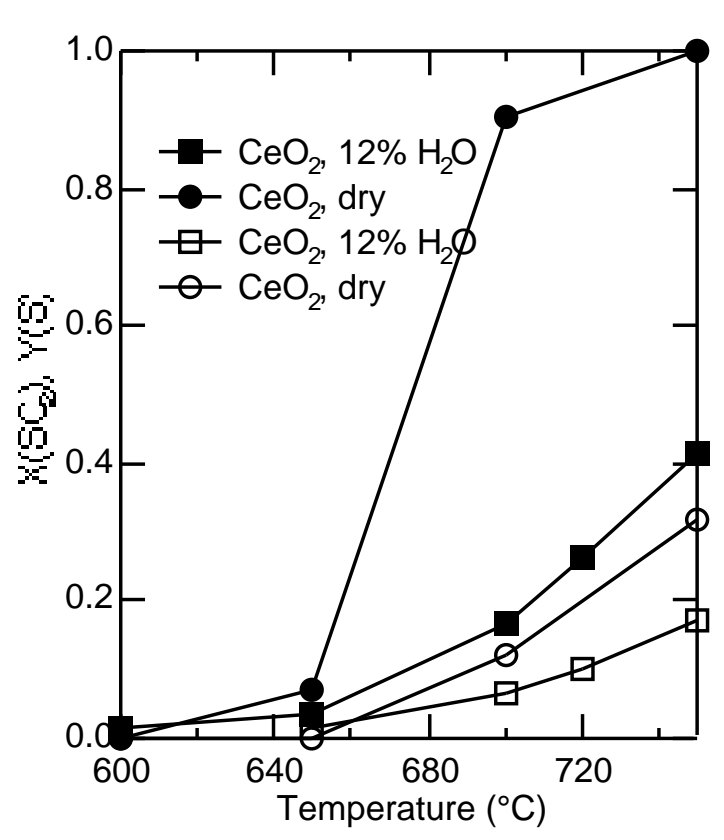

Figure 4-2. Effect of adding water on the activity of $\mathrm{CeO}_{2}$. Samples were calcined at $650^{\circ} \mathrm{C}$. Reaction conditions: $1 \% \mathrm{SO}_{2}, 0.5 \%$ $\mathrm{CH}_{4}, 12 \% \mathrm{H}_{2} \mathrm{O}$, contact time $=0.36 \mathrm{~g} \mathrm{~s} / \mathrm{cm}^{3}$.

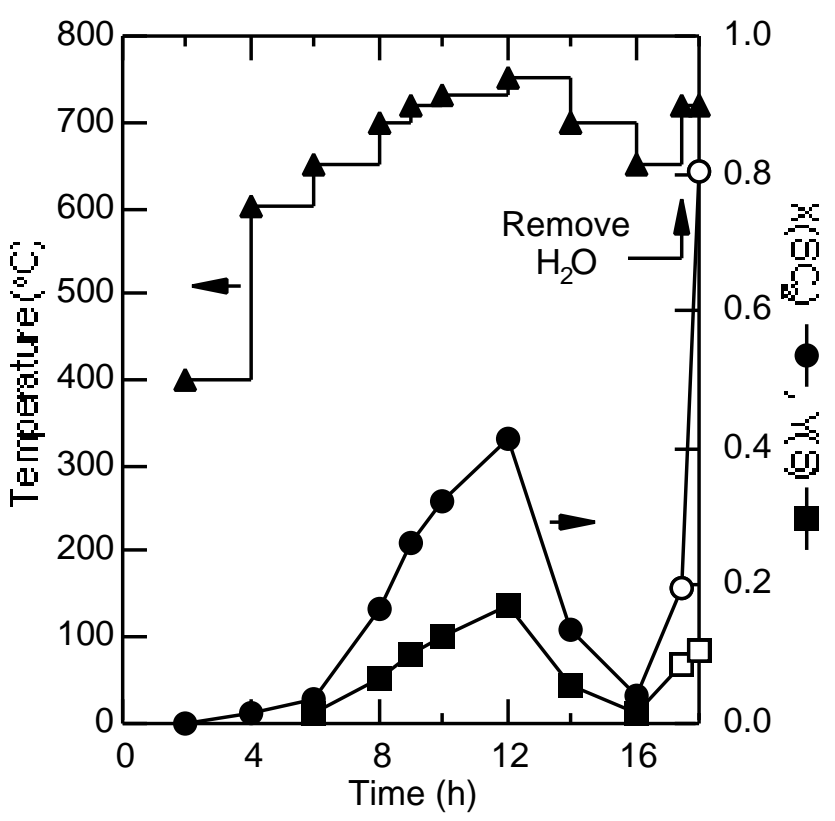

Figure 4-3. Demonstration of the recovery in the activity of $\mathrm{CeO}_{2}$ when water is removed from the feed stream. Conditions for the first 17 hours were the same as those in Figure 4-2.

\section{Arthur D. Little}

Reactor. Work continued on the larger scale reactor at ADL. Because this reactor will be used with substantial flows of toxic gases it was deemed necessary to equip it with a safety interlock system, an afterburner to handle the reactor effluent as well as extensive ventilation. Much of the hardware is now in place and will be tested in the near future.

Process simulation. Initial data from experiments being conducted at Tufts, wherein methane was used as the reducing agent, indicated the following:

- As temperature is increased, to afford higher conversion of $\mathrm{SO}_{2}$ to elemental sulfur, production of undesirable species such as $\mathrm{H}_{2} \mathrm{~S}$ and COS increases.

- While chemical conversion of $\mathrm{SO}_{2}$ is enhanced by excess reducing agent, production of $\mathrm{H}_{2} \mathrm{~S}$ and COS outpaces gains in sulfur yield.

- To keep $\mathrm{H}_{2} \mathrm{~S}$ and COS to acceptable levels (say <1\%), the maximum yield of elemental sulfur that can be achieved appears to be about $20 \%$.

Given the need for conversion of $\mathrm{SO}_{2}$ to $\mathrm{S}$ to be upwards of $95 \%$, these results were not encouraging. In discussion it was agreed that testing with carbon monoxide $(\mathrm{CO})$ as the reducing agent should be done, to see whether $\mathrm{CO}$ offered enhanced prospects for conversion.

The observed level of conversion, although low, could be accommodated if tail gas could be recycled. This would imply the need for significant custom engineering to couple the sulfur recovery subsystems with the primary plant equipment, namely the boiler or gasifier, and would likely be characterized by unattractive economics. To clarify this point, we used the process 
analysis tool we developed for this program to examine the gross implications of recycling the sulfur recovery waste stream.

Energy considerations were not a part of this analysis. The objective was simply to quantify material flows, develop an understanding of the implications insofar as equipment size requirements, and make an assessment as to whether a recycling strategy could be viable. First a baseline case was defined, for both a utility boiler and an IGCC application, based on engineering judgments and expected technology improvements. Then, a sensitivity analysis was conducted to examine the effect of several key design parameters on recycle requirements for the system as a whole. These were as indicated below.

\begin{tabular}{|l|l|l|}
\hline Parameter & Baseline & Sensitivity \\
\hline Adsorber efficiency & $90 \%$ & $\$ 9 \%$ \\
\hline Adsorber regeneration timescale & $0.80 \%$ & $\$ .88 \%$ \\
\hline Regenerator gas $\mathrm{O}_{2}$ concentration (IGCC) & $2.0 \%$ & $\$ .0 \%$ \\
\hline Increased sulfur yield & $60 \%$ & $\$ 5 \%$ \\
\hline Reducing gas stoich. equivs. & $2.0 \%$ & $.0 \%$ \\
\hline
\end{tabular}

The results are effected strongly by the assumed sulfur cleanup technology. For IGCC, zinc oxide based technology using vitiated air was assumed; for a utility boiler, copper oxide using based technology using methane was assumed. These two technologies have very different requirements regarding regenerant gas volumes, as is indicated quite strongly in the results of the analysis.

$I G C C$ : For the parameter sensitivities considered, mole flow increases associated with recycle were roughly $25-50 \%$ over those associated with the corresponding cases involving no recycle. Recycle for this technology configuration is deemed unacceptable.

Boilers: For the parameter sensitivities considered, mole flow increases associated with recycle were roughly $0.5-1.0 \%$ over those associated with the corresponding cases involving no recycle. Recycle for this technology appears tenable on the basis of economics for new plants. No ready conclusions can be made for the retrofit market.

Subsequently we adapted our process analysis tool to enable calculations regarding process economics. In particular it was of interest to quantify effective deratings associated with the tapping of carbon monoxide from the syngas stream produced in IGCC. Additionally it was of interest to develop a technology cost target based on competing technologies, i.e. lime-based desulfurization and Claus plant sulfur recovery.

An attempt has been made to estimate reducing gas costs, which appear to dominate the capital and operating cost picture.

In IGCC, syngas produced in the process can be used as the reducing agent for sulfur recovery. Taking a coal sulfur content of $3 \%$ on a mass basis, a stoichiometric amount of reducing gas represents a requirement of approximately $4 \%$ of the syngas produced. Assume the following:

- Base plant capacity of $500 \mathrm{MW}$

- Base plant installed cost of $\$ 1,500 / \mathrm{kW}$

- Cost-capacity scaling exponent of 0.6

The installed cost of the base plant is $\$ 750$ Million. The cost of an oversized plant which could divert $4 \%$ of product for the sulfur recovery function, would be : 


$$
\text { Cost }(\text { Oversize })=\text { Cost }(\text { Base }) *((500 / 0.96) / 500)^{0.6}=\$ 750 \mathrm{MM} / 0.96^{0.6}=\$ 769 \mathrm{MM}
$$

suggesting a capital equipment investment for reducing gas supply of on the order of $\$ 20$ Million. At an annual capacity factor of $70 \%$, the IGCC facility would produce 3.1 Billion kilowatt-hours a year. If the reducing gas supply equipment were to be capitalized over ten years, this would correspond to a charge increment to consumers of 0.07 cents $/ \mathrm{kWh}$, or about $1 \%$ of typical electricity prices in the US. The annual cost of the equipment would be about $\$ 2$ Million.

The cost of coal required to generate the requisite amounts of syngas represents the predominant operating cost. Using a coal cost of $\$ 1.30 / \mathrm{MMBtu}$, these operating costs amount to approximately $\$ 44 /$ ton of sulfur recovered. In a $500 \mathrm{MW}$ plant running on coal with a $3 \%$ sulfur content, approximately 30.5 kilotons of sulfur would be recovered each year. The cost of coal associated with reducing gas requirements is approximately \$1.4 Million.

The total costs of reducing agents associated with sulfur recovery appears to be on the order of \$3-4 Million/year.

Previously it had been thought that natural gas would be the preferred reducing gas. However, in light of the Tufts data, it does not appear that methane is sufficient for producing sulfur yields consistent with the economic requirements for the technology. If it could be used, and if natural gas were available at $\$ 2.50 / \mathrm{MMBtu}$, the cost per unit of sulfur recovered would be roughly $\$ 47 /$ ton.

For a $500 \mathrm{MW}$ power plant, running on coal with a $3 \%$ sulfur content, about 37.5 kilotons of sulfur would be recovered annually. The associated cost of natural gas would be on the order of $\$ 1.8$ Million. Auxiliary equipment would include flow delivery and control systems, and would add some expense. The total reducing gas cost would thus be about \$2.0 Million/year.

\section{Engelhard}

Catalyst preparation. Engelhard prepared the first set of monoliths containing a sulfur reduction catalyst. The chosen catalyst was a $2 \% \mathrm{Cu} / \mathrm{CeO}_{2}$ which was prepared by co-precipitation according to the standard recipe from Tufts. This catalyst was then mixed with a small quantity of a silica binder (ca. $2 \mathrm{wt} \%$ ) and then wash coated on to a $400 \mathrm{cell} / \mathrm{in}^{2}$ monolith. The monolith was cored to yield smaller, cylindrical samples, each about $4.5 \mathrm{~cm}$ in diameter and $7 \mathrm{~cm}$ in length. A portion of one monolith was tested at Tufts and was found to exhibit an activity for $\mathrm{SO}_{2}$ reduction consistent with the loading of the catalyst. These monoliths will be used in the first test of the bench-scale reactor being constucted at Arthur D. Little.

\section{References:}

(1) Henzel, D. S.; Ellision, W. Proceedings: $1990 \mathrm{SO}_{2}$ Control Symposium 1990, Volume 1, 3B-27.

(2) Liu, W. . Sc.D. Thesis, Massachusetts Institute of Technology, 1995.

(3) Liu, W.; Sarofim, A. F.; Flytzani-Stephanopoulos, M. Applied Catalysis B: Environmental 1994, 4, $167-186$.

(4) National Coal Association "Steam Electric Plant Factors,", 1992.

(5) Trovarelli, A. Catal. Rev., Sci. Eng. 1996, 138, 439-520.

(6) Tyson, S. Proceedings of the 9th Annual International Pittsburgh Coal Conference 1992. 